\title{
Análise sismoestratigráfica da seção rifte da Bacia de Santos, Brasil
}

\author{
Andrea Arias RAMIREZ ${ }^{1}$, Juliano KUCHLE², Renata dos Santos ALVARENGA ${ }^{3}$, Claiton SCHERER ${ }^{2}$ \\ \& Karin GOLDBERG ${ }^{4}$
}

1,3 Programa de Pós-graduação em Geociências, Universidade Federal do Rio Grande do Sul. Av. Bento Gonçalves, 9500, CEP 91540-000, Porto Alegre, RS, Brasil. E-mail: afar82@gmail.com, renatalvarenga@yahoo.com.br.

2 Programa de Geologia do Petróleo, Departamento de Paleontologia e Estratigrafia, Programa de Pós-graduação em Geociências, Instituto de Geociências, Universidade Federal do Rio Grande do Sul. Av. Bento Gonçalves, 9500, CEP 91540-000, Porto Alegre, RS, Brasil. E-mail: juliano.kuchle@ufrgs.br, claiton.scherer@ufrgs.br.

4 Departamento de Mineralogia e Petrologia, Instituto de Geociências, Universidade Federal do Rio Grande do Sul, Av. Bento Gonçalves, 9500, CEP 91540-000, Porto Alegre, RS, Brasil. E-mail: karin.goldberg@ufrgs.br.

Recebido em 04/2014. Aceito para publicação em 09/2015.

Versão online publicada em 11/12/2015 (www.pesquisasemgeociencias.ufrgs.br)

Resumo - A Bacia de Santos, apesar de uma das principais bacias atualmente no Brasil exploradas
devido à importância do pré-sal, possui pouca informação geológica, como registros de poço, sísmi-
ca 3D e sísmica 2D de boa qualidade na seção rifte. O presente trabalho visa à integração da análise
sismoestratigráfica e proposição de um modelo de evolução tectonoestratigráfica para a seção rifte
da bacia. A análise sismoestratigráfica envolveu a interpretação dos refletores, que é a base da
identificação das unidades sismoestratigráficas e a caracterização das sismofácies. Como resultado,
foi obtida a definição de 16 unidades sismoestratigráficas e quatro sismofácies (incluindo o sag), e
o desenvolvimento das cartas cronoestratigráficas de eventos adaptadas para o contexto sísmico.
Com base no ajuste do modelo de padrões de empilhamento para mudanças na atividade tectônica,
foram delimitados os tratos de sistemas tectônicos de início de rifte, de alta atividade tectônica, de
baixa atividade tectônica e o pós-rifte, representado pelo sag. O desenvolvimento de cada um dos
tratos respondeu a variações dos fatores controladores das bacias lacustres, interpretado como o
balanço relativo entre as taxas de mudanças do espaço de acomodação gerado pela tectônica e o
aporte sedimentar influenciado pelo clima. Palavras-chave: Bacia de Santos, seção rifte, unidades sismoestratigrafia, sismofácies, tratos de sistemas tectônicos.

Abstract - SEISMIC STRATIGRAPHIC ANALYSIS IN THE RIFT SECTION OF SANTOS BASIN, BRAZIL. The
Santos Basin, despite its surmount significance due to the pre-salt reservoirs, has limited geological
information well-logs, 3D seismic or good quality 2D seismic for the rift section. The present work
aims at integrating seismic stratigraphic analysis and proposing a tectonic-stratigraphic evolution
model for the rift section of the basin. Seismic stratigraphic analysis involved interpretation of re-
flectors, which is the base of seismic stratigraphic units identification and seismic facies characte-
rization. The result was the definition of 16 seismic stratigraphic units, four seismic facies (inclu-
ding the sag), and the development of chronostratigraphic charts of events adapted to the seismic
context. Based on the adaptation of the stacking patterns to tectonic activity changes model, it was
possible to delimit the rift initiation system tract, the high tectonic activity system tract, the low
tectonic activity system tract and the post-rift, represented by the sag. The development of each
tectonic system tract responded to variations in controlling factors of the lacustrine basin, inter-
preted as the relative balance between the rate changes in the accommodation space generated by
tectonic and sediment supply influenced by climate. Keywords: Santos Basin, rift section, seismic facies, tectonic system tract. 


\section{Introdução}

Nos últimos anos, inúmeros trabalhos têm enfatizado a evolução tectonoestratigráfica de bacias riftes, focando na influência da tectônica na geometria da bacia e na razão entre a taxa de influxo sedimentar e a taxa de acomodação durante os diferentes estágios do rifteamento (e.g. Prosser, 1993; Bosence, 1998; Gawthorpe \& Leeder, 2000; Morley, 2002; Kuchle \& Scherer, 2010). Entretanto, há poucos estudos detalhando a assinatura sismoestratigráfica de cada um dos estágios evolutivos do rifteamento que permitam o estabelecimento de critérios precisos para o reconhecimento e diferenciação entre eles. Além disso, não existe base metodológica consolidada sobre a análise sismoestratigráfica de bacias rifte que possa ser aplicada universalmente.

Com o objetivo de avaliar a evolução estrutural, estratigráfica, e os potenciais reservatórios da seção rifte da Bacia de Santos com base em dados sísmicos 2D, foi realizado o mapeamento e interpretação dos refletores sísmicos, com a identificação dos padrões de empilhamento, reconhecimento das superfícies chaves e dos tratos de sistemas tectônicos (conforme Kuchle \& Scherer 2010), desenvolvendo-se assim um arcabouço sismoestratigráfico para este intervalo. A interpretação dos refletores sísmicos se baseia na reflexão sísmica. Estes podem ter terminações em onlap, downlap, toplap e truncamentos erosivos, que são os principais critérios para o reconhecimento das unidades sismoestratigráficas (Mitchum et al., 1977). A análise das sismofácies consiste na descrição e na interpretação geológica dos parâmetros de reflexões sísmicas, incluindo a configuração, continuidade, amplitude, frequência e intervalo de velocidade. Com estas informações, elabora-se a carta cronoestratigráfica de eventos, conforme determinado inicialmente por Wheeler (1958) e adaptado para o contexto sísmico por Vail et al. (1977).

Este trabalho fundamenta-se exclusivamente em dados sísmicos e, por isto, para fazer o mapeamento sismoestratigráfico da seção rifte foi adaptado o modelo de Prosser (1993) e Kuchle \& Scherer (2010). Estes usam os padrões de empilhamento para propor modelos de evolução das bacias tipo rifte baseados nas mudanças da atividade tectônica. A partir destas informações, foram definidas as superfícies e os tratos de sistemas tectônicos da seção rifte da Bacia de Santos.

\section{2 Área, materiais e métodos}

\subsection{Geologia regional}

A Bacia de Santos ocorre em uma vasta porção da margem continental leste, com orientação geral SW-NE, localizada na região do sudeste brasileiro. Está limitada ao norte pelo Arco de Cabo Frio, ao sul pela Plataforma de Florianópolis, e a oeste é limitada pela Serra do Mar, uma feição fisiográfica que a confina ao domínio oceânico (Milani et al., 2000). A bacia recobre uma área de cerca de $350.000 \mathrm{~km}^{2}$, no litoral sul do Rio de Janeiro, São Paulo, Paraná e norte de Santa Catarina. A figura 1 apresenta sua localização e as linhas sísmicas interpretadas dentro da área de estudo.

A evolução da fase rifte da Bacia de Santos resulta da propagação da ruptura das placas sulamericana e africana, no Eocretáceo. 0 rifte Sul-Atlântico propagou-se de sul para norte, controlado pela distribuição de tensões regionais que condicionou a atenuação litosférica em ampla faixa de deformação (Chang et al., 2008).

$\mathrm{Na}$ Bacia de Santos são reconhecidas falhas extensionais lístricas e de alto ângulo que afetam a crosta continental, rochas vulcânicas do Barremiano ao início do Aptiano e depósitos clásticos; domos do sal no talude continental; falhas lístricas, inversas e thrusts geradas pelo sal em sedimentos do Cretáceo Superior e Paleogeno; falhas limitando meio-grábens causados pela fase extensional entre o Hauteriviano e Barremiano Superior (Contreras et al., 2010).

A Bacia de Santos recobre o Platô de São Paulo, que ao longo da margem leste brasileira é a única característica altamente anômala estendida na litosfera continental (Milani \& Thomaz Filho, 2000). A borda leste da placa sulamericana (norte da Dorsal de São Paulo) apresentou evolução estrutural mais ou menos síncrona, devido aos efeitos dos deslocamentos continentais entre a América do Sul e África desde o Eocretáceo. A ruptura do Gondwana teria se dado ao longo de um extenso sistema de fraturas, que se estendia da Argentina até o nordeste de Brasil. Nas áreas relativas à Bacia de Santos, ocorreu acréscimo de material vulcânico para o fundo das calhas do rifte (Macedo, 1990).

0 arcabouço cronoestratigráfico da Bacia de Santos está definido em sequências deposicionais. Este trabalho é concentrado na Supersequência Rifte, na qual o registro sedimentar inicia no Hauteriviano e prolonga-se ao início do Aptiano, sendo subdividido em três sequências deposicionais denominadas: a) K20-K34, composta por derrames basálticos eocretáceos sotopostos ao 
preenchimento sedimentar de praticamente toda a bacia, denominada Formação Camboriú, b) K36, correspondente à Formação Piçarras, composta por leques aluviais de conglomerados e arenitos polimíticos constituídos de fragmentos de basalto, quartzo, feldspato, nas porções proximais, e por arenitos, siltitos e folhelhos de composição talco-estevensítica nas porções lacustres, e c) K38, correspondente à Formação Itapema (Grupo Guaratiba), caracterizada por intercalações de calcirruditos e folhelhos escuros ricos em matéria orgânica nas porções mais distais, conglomerados e arenitos de leques aluviais nas porções proximais desta unidade. Os calcirruditos são constituídos por fragmentos de conchas de pelecípodes que frequentemente encontram-se dolomitizados e/ou silicificados (Moreira et al., 2007). A sequência sag, composta por depósitos de águas muito rasas em um lago ou mar epicontinental, é caracterizada por calcários estromatolíticos, laminitos microbiais, microbiolitos ricos em talco e argilas magnesianas e folhelhos carbonáticos, provavelmente depositados em ambientes alcalinos com ocorrência subordinada de coquinas; ocorre sobre os sedimentos da Formação Itapema de idade mínima de 123,1 Ma e está sotoposta à Formação Ariri de idade máxima de 113 Ma (Moreira et al., 2007). A figura 2 apresenta a super sequência Rifte, com as unidades correspondentes às sequências deposicionais, e informações acerca da tectônica e magmatismo, geocronologia e ambiente deposicional.

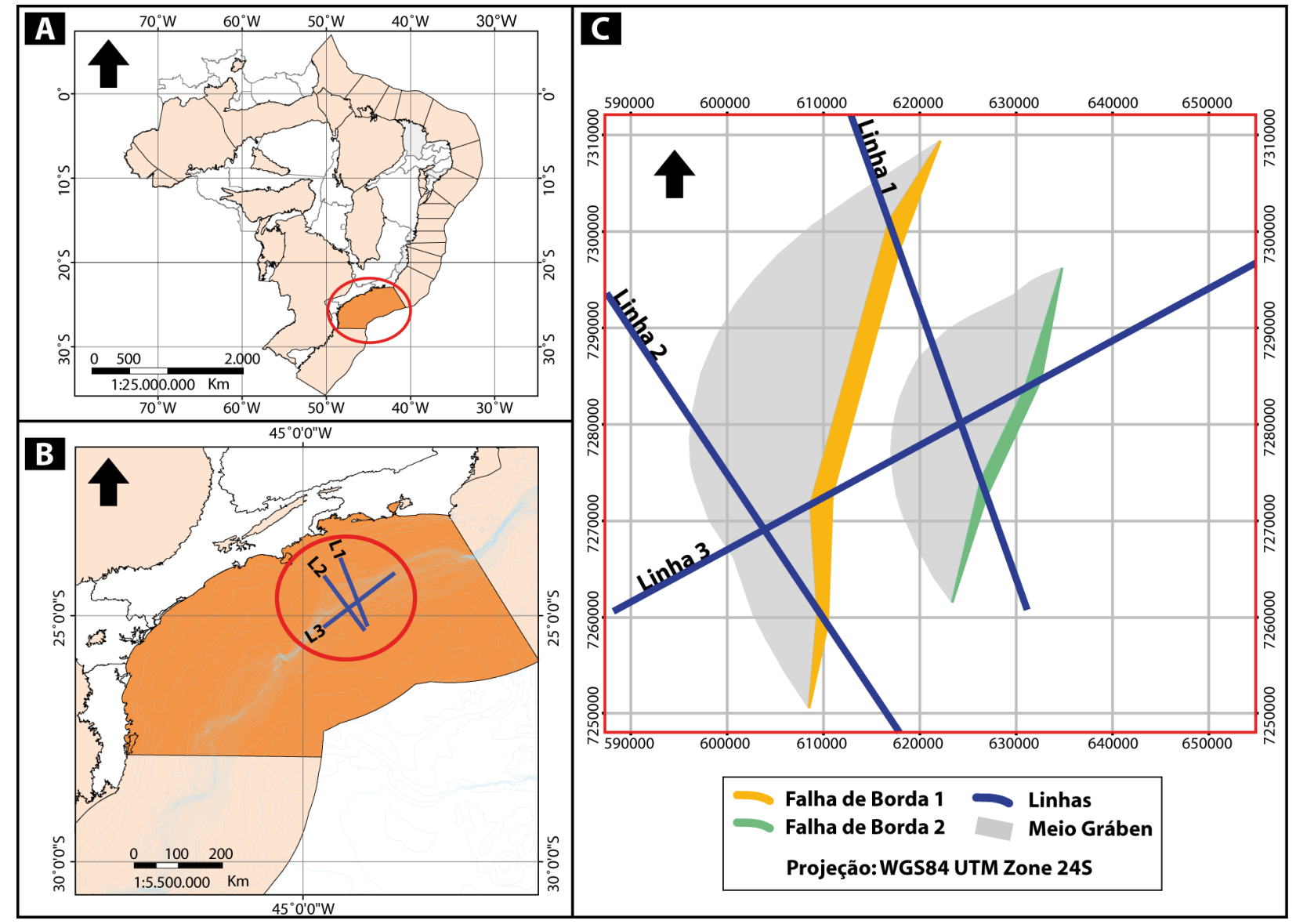

Figura 1. Localização da área estudada. A) Localização da Bacia de Santos no Brasil; B) Localização das linhas sísmicas dentro da Bacia de Santos; C) Orientação das falhas de borda e das calhas dos meio-grábens interpretados conforme a direção das linhas sísmicas.

\subsection{Materiais e métodos}

Para a análise sismoestratigráfica foram escolhidas três linhas sísmicas 2D de boa qualidade e com definição suficiente das sismofácies que permitiram a definição do arcabouço estratigráfico. Os levantamentos sísmicos foram proporcionados pela Agência Nacional de Petróleo, Gás e Biocombustíveis (ANP) e estão distribuídos ao longo das bacias de Campos e Santos.
Inicialmente foi feita a interpretação dos refletores baseada nas terminações estratais (onlap, downlap, toplap e truncamentos erosivos), que se referem às relações geométricas entre os estratos e as superfícies estratigráficas contra a qual terminam, podendo ser observadas na superfície, em conjuntos de dados do subsolo, afloramentos, e seções sísmicas (Catuneanu, 2006). Estes são os principais critérios para o reconhecimento das unidades sismoestratigráficas (Mitchum et al., 1977). 


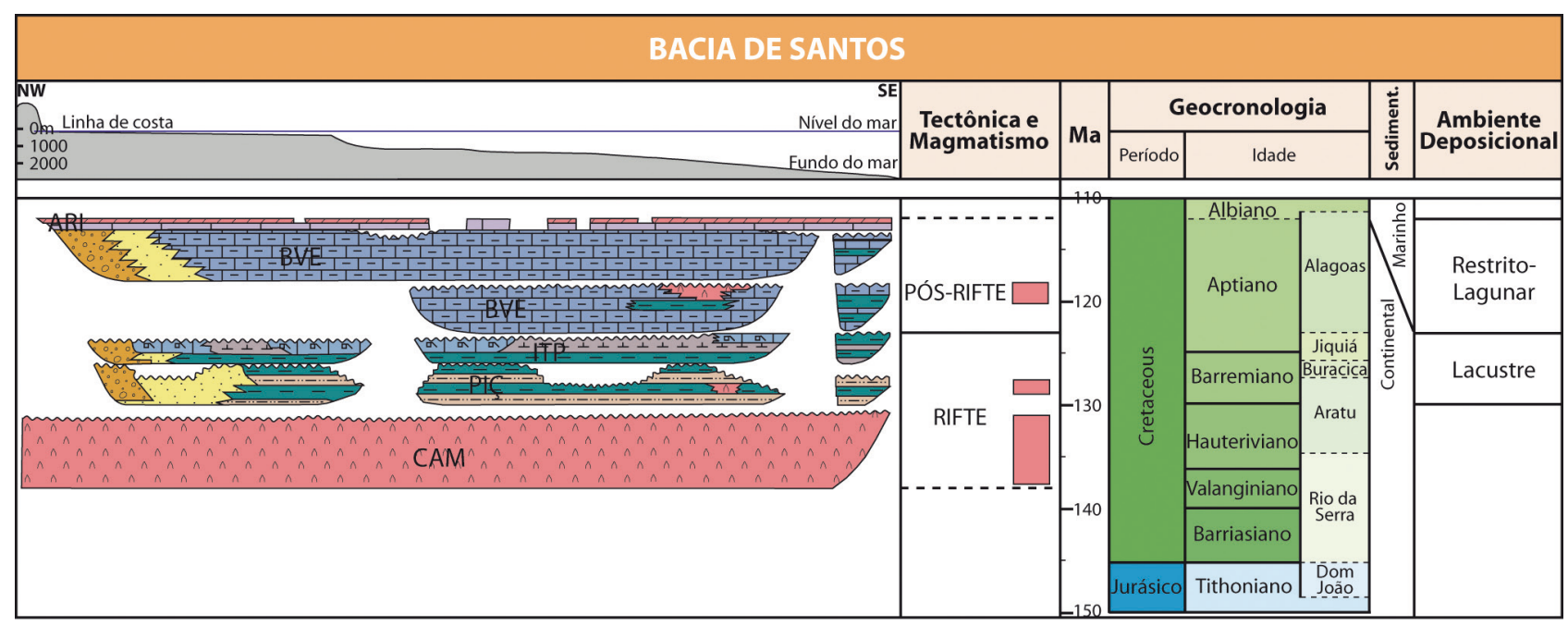

Figura 2. Carta estratigráfica da seção rifte da Bacia de Santos (modificada de Moreira et al. 2007).

Com a informação obtida dos refletores e o auxílio dos atributos sísmicos Cosine Phase, Sweetness, Relative Acoustic Impedance (RAI), RMS Amplitude foram caracterizados os limites dos meio-grábens, falhas, discordância pós-rifte e base do sal. As seções sísmicas foram interpretadas em tempo no software Petrel versão 2009. Os atributos sísmicos são descrições matemáticas da forma característica de um traço sísmico em intervalos de tempo específicos. Estes atributos permitem aos intérpretes extrair mais informações dos dados sísmicos (Schroeder, 2011). Na figura 3 pode-se observar a expressão sísmica e a utilidade de cada atributo.

Com base nos conjuntos de terminações dos refletores ao longo de uma superfície, foram individualizadas unidades sismoestratigráficas, que são conjuntos de estratos cronoestratigraficamente relacionados, com expressão sísmica, limitados no topo e na base por terminações de refletores (Mitchum et al., 1977). As unidades sismoestratigráficas acabam por equivaler assim aos tratos de sistemas conforme definido por Brown Jr. \& Fischer (1977), conjunto de estratos geneticamente relacionados, o que não necessariamente implica na ocorrência (nem exclusão) de discordâncias como superfícies limítrofes. As superfícies estratigráficas marcam alterações nos padrões de empilhamento e podem servir como limites de tratos de sistemas (Catuneanu et al., 2011). Assim, as unidades sismoestratigráficas são unidades deposicionais relacionadas a um período de tempo específico e distinto das unidades abaixo e acima.

A análise de fácies sísmicas é baseada na configuração de reflexões e de outros parâmetros sísmicos, incluindo a configuração de reflexão, amplitude, continuidade, frequência e velocidade de intervalo. Estes parâmetros são interpretados como a expressão de certos grupos litológicos, que, a partir de suas características deposicionais, podem estabelecer ciclos no âmbito da sequência sísmica (Mitchum et al., 1977). As alterações de nível base ou nível relativo do mar, que é o efeito combinado de subsidência e eustasia, pode controlar o potencial de acomodação dos sedimentos e a distribuição de fácies dentro dos tratos de sistemas (Haq et al., 1987). Com a avaliação dos parâmetros mais o auxílio dos atributos sísmicos são definidas as fácies sísmicas.

Após a definição das unidades sismoestratigráficas e as fácies sísmicas, é elaborada a carta cronoestratigráfica de eventos, conforme determinado por Wheeler (1958) e adaptado para o contexto sísmico por Vail et al. (1977). Na carta cronoestratigráfica, a geometria da unidade fornece o contexto paleogeomorfológico no qual ela foi depositada, e a disposição espacial das unidades mostra o arranjo arquitetural dos sistemas deposicionais durante o preenchimento da bacia, indicando os momentos de mudança (Kuchle \& Scherer, 2010).

Sequências de superfícies estratigráficas são fundamentais na construção do arcabouço cronoestratigráfico para a sucessão sedimentar em análise. Tais superfícies podem ser identificadas com base em vários critérios, como: 1) a natureza do contato (conformável ou discordante); 2) a natureza dos sistemas de deposição que estão em contato com toda a superfície; 3 ) tipos de terminações dos refletores associados a essa superfície; e 4) as tendências de deposição identificadas abaixo e acima da superfície de contato (Catuneanu, 2006).

Com a integração das informações obtidas em cada fase deste trabalho, foram identificadas as superfícies chaves que limitam os tratos de sistemas tectônicos, e que por fim indicam os estágios de 
desenvolvimento da seção rifte da Bacia de Santos. O modelo evolutivo foi adaptado do modelo de Prosser (1993) e Kuchle \& Scherer (2010), que usam padrões de empilhamento para propor um modelo de evolução das bacias tipo rifte baseado nas mudanças da atividade tectônica, mantendo a denominação de tratos de sistemas tectônicos, mas sem um padrão de empilhamento determinável para cada trato.

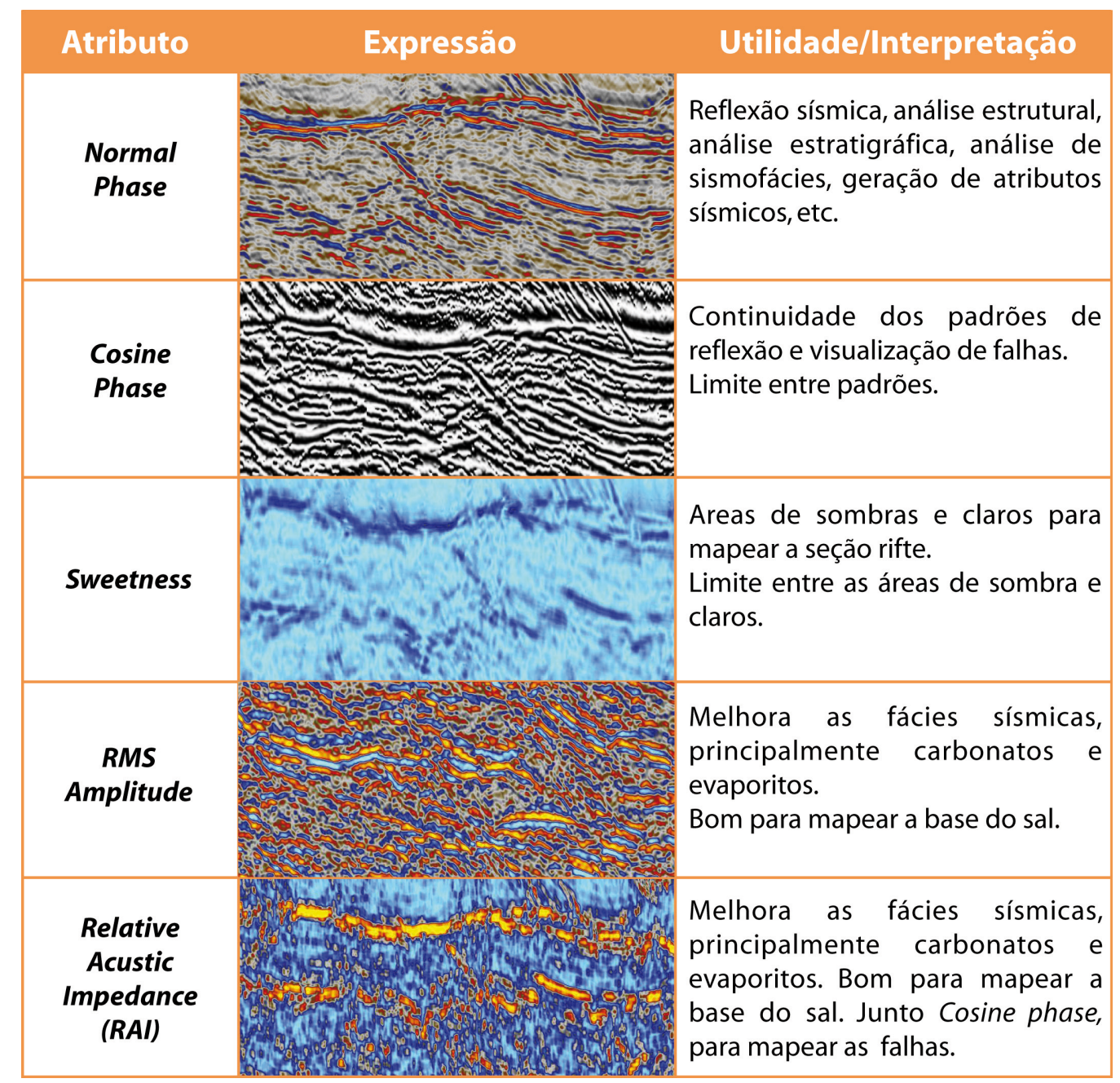

Figura 3. Expressão, utilidade e interpretação dos atributos sísmicos gerados a partir de uma linha sísmica em normal phase.

\section{Resultados}

\subsection{Sismoestratigrafia}

Embora as sequências deposicionais também possam ser observadas em perfis de poço, afloramentos e testemunhos de sondagem, o método baseado nas reflexões sísmicas é a ferramenta mais eficaz para a aplicação de conceitos de sequência. As reflexões sísmicas são geradas por superfícies estratais com diferentes propriedades acústicas, e por esta razão elas seguem uma tendência paralela dos estratos, tendo um significado cronoestratigráfico. Portanto, é possível fazer correlações cronoestratigráficas usando padrões de reflexões sísmicas (Mitchum et al., 1977).

Para a realização da análise sismoestratigráfica foram selecionadas três linhas sísmicas 2D com melhor qualidade, que permitiram a identificação da geometria do meio-gráben (falha de borda e margem flexural) e a definição do arcabouço estratigráfico dentro da seção rifte. As linhas 1 e 2 são linhas dip com direção NW-SE, e a linha 3 é uma linha strike com direção SW-NE, localizadas no setor nordeste da bacia (Fig. 1). As linhas foram trabalhadas em tempo (TWT).

\subsubsection{Interpretação dos refletores}

Inicialmente, foi feito o mapeamento dos refletores de cada uma das linhas sísmicas escolhidas. Com o atributo sísmico Cosine Phase foram definidas as falhas de borda e outras falhas secundárias que afetam os meio-grábens, o limite basal (Topo da Fm. Camboriú) e o topo do intervalo de estudo, delimitados pela base do sal. As linhas se 
encontram no intervalo entre 4500 e 7000 milissegundos (TWT). Na seção sísmica trabalhada, a falha de borda foi identificada no leste e a margem flexural no oeste da seção.

Na Linha 1 foi delimitado o primeiro meio-gráben, que apresenta diferentes padrões nas reflexões ao longo da linha (Fig. 4). Contudo, se observa uma configuração divergente, tipo wavy, no lado oeste; restrito ao lugar onde foi definida a falha de borda ocorre um padrão caótico de baixa continuidade (Fig. 4).

Na Linha 2 foi delimitado o segundo meio-gráben, o qual tem a mesma disposição estrutural do primeiro. Os refletores apresentam uma disposição tipo wavy no lado oeste, caótica e hummocky no lado leste da seção; do centro até o topo do meio-gráben identifica-se um padrão subparalelo. Em geral a continuidade e amplitude são baixas, com algumas exceções onde os refletores têm alta continuidade e amplitude (Fig. 5).

Na Linha 3 (com disposição strike) foi possível mapear os meio-grábens 1(MG-1) e 2 (MG-2), identificados previamente nas linhas dip, onde as falhas de borda foram interpretadas a leste e as margens flexurais a oeste da seção. O MG-2 apresenta, na porção oeste até o centro, uma configuração de refletores divergentes; no sul, uma configuração wavy, e caótico, restrito à falha de borda. Do centro do MG-2 até o centro do MG-1, os refletores exibem uma configuração subparalela e na zona leste são ondulados (Fig. 6).

\subsubsection{Unidades sismoestratigráficas}

Baseados na continuidade e nas terminações dos refletores foram definidas 16 unidades sismoestratigráficas (US) que possuem um significado temporal e proporcionam a compreensão do desenvolvimento e evolução dos meio-grábens caracterizados. As US e sismofácies definidas nas linhas sísmicas 1, 2 e 3 encontram-se ilustradas nas figuras 7,8 e 9 , respectivamente.

A US 1 está limitada na base pelo topo da Formação Camboriú (rochas vulcânicas). Esta US foi identificada na Linha 2 e no meio-gráben oeste da linha 3. A US 2 deposita-se em downlap sobre a US 1 , da mesma forma que as US 3, US 4 e US 5. As US 2, US 3, US 4 e US 5 são reconhecidas somente na Linha 2 (Fig. 8A).

A US 6 é delimitada na base pelo topo da Formação Camboriú na linha 1 e no meio gráben leste da Linha 3 (Fig. 9A). Na Linha 2 e no meio-gráben oeste da Linha 3, a US 6 ocorre em downlap sobre a US 1. A US 7, em alguns lugares das linhas 1 e 3, a base é delimitada pelo topo da Formação Cam- boriú. Essa unidade foi interpretada em todas as linhas (Figs. 7A, 8A e 9A). A US 8 deposita-se em downlap sobre a US 7, assim como a US 9 sobre a US 8. As unidades sismoestratigráficas 7 e 8 só foram interpretadas no meio-gráben 1 (Fig. 7A). A US 10 é depositada ao longo das estruturas, no meio-gráben 2, e as US 5, 7 e 10 se encontram em toplap contra a US 11.

A US 11 foi interpretada ao longo das estruturas na Linha 3, onde se deposita em downlap sobre a US 10. A US 12 deposita-se em downlap sobre a US 11 nas linhas 1 e 3 , enquanto na Linha 2, a US 12 se apresenta em onlap sobre a US 13 (Fig. 8A). A US 13 na Linha 3 não é contínua, e termina em onlap sobre a US 14, reaparecendo em toplap na US 14, no centro da estrutura (Fig. 9A). A US 14 está limitada no topo pela discordância pós-rifte ao longo das estruturas. Na Linha 1 foi interpretada do centro para a zona leste (Fig. 7A), enquanto na Linha 2 se encontra restrita no centro (Fig. 8A). A discordância pós-rifte corresponde a uma possível superfície de exposição subaérea, com intensa erosão (representada por truncamentos erosivos) na Linha 1 das unidades 9, 1, 11, 12, 13 e 14; na Linha 2 das unidades $3,4,11,12,13$ e 14, e na Linha 3 das unidades 7, 10, 12, 13, e 14 (Figs. 7A-9A).

Por fim, são depositadas as US 15 e US 16, marcando a deposição da fase sag (pós-rifte), limitada pela discordância de pós-rifte.

\subsubsection{Sismofácies}

0 processo de análise das sismofácies envolve a delimitação e a interpretação da geometria da reflexão, continuidade, amplitude, frequência, e intervalo de velocidade. Cada um destes parâmetros sísmicos contém informações de significado estratigráfico (Vail et al. 1977). Assim, a identificação de comportamentos distintos baseados nestes parâmetros nas linhas sísmicas analisadas possibilitou a caracterização de quatro sismofácies: a) SF-A, interpretada como depósitos da falha de borda, b) SF-B, interpretada como depósitos de sedimentos finos, c) SF-C, interpretada como litologias carbonáticas, e d) SF-D, pertencente à fase sag, não analisada por estar fora do intervalo de estudo.

A sismofácies A (SF-A) possui refletores com uma resposta sísmica caótica, sem continuidade, e de baixa amplitude. Na Linha 1 esta sismofácies aparece na unidade sismoestratigráfica (US) 7, onde tem seu maior desenvolvimento e é encontrada novamente na US 11 , onde se observa uma notável diminuição deste padrão (Fig. 7A). Na Linha 2, a SF-A tem uma disposição mais contínua. Sua ocorrência inicia na US 6, passando pelas US 7, 

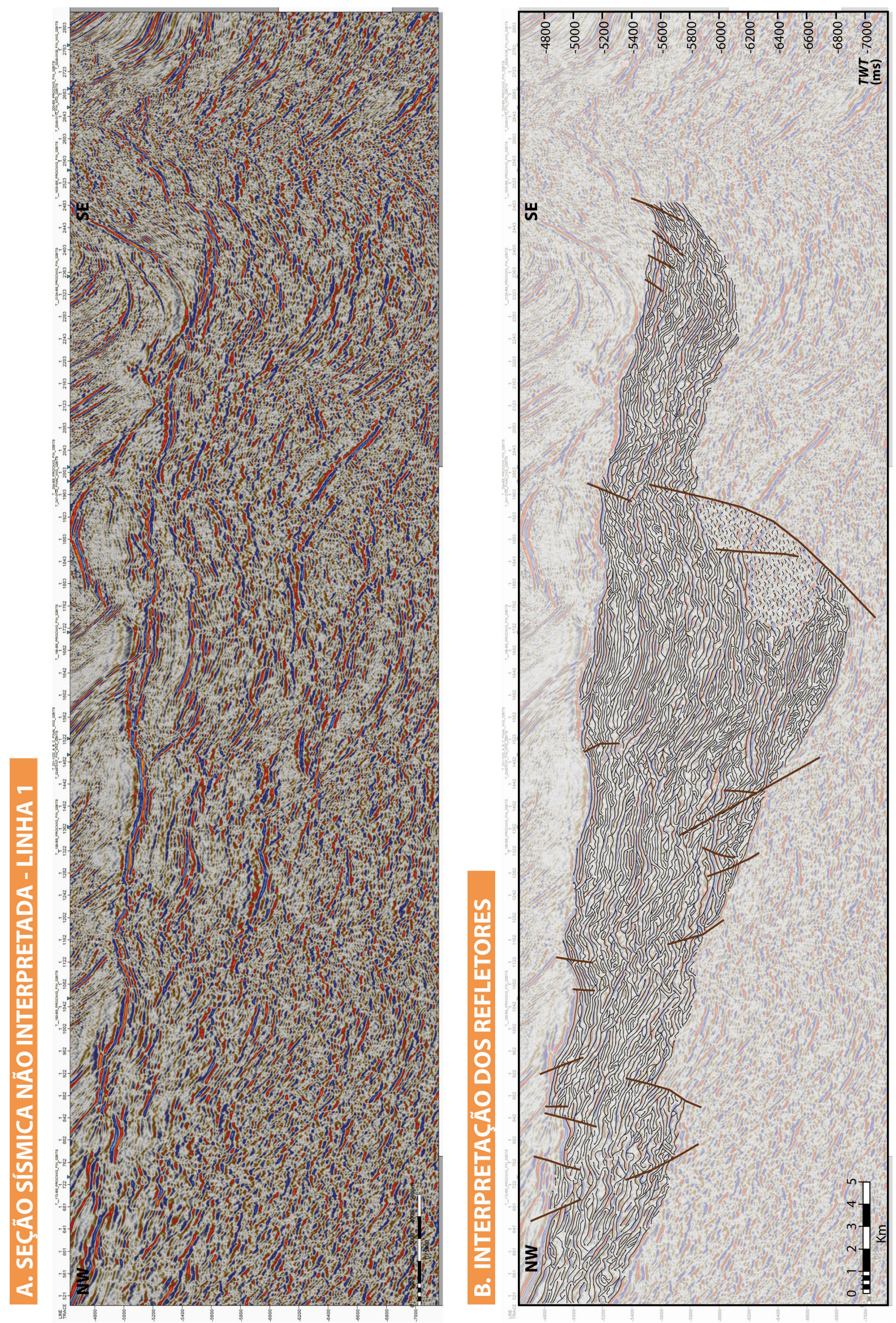

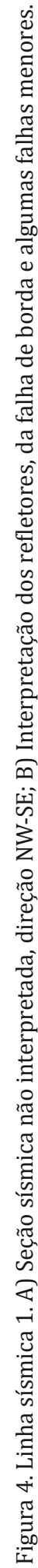



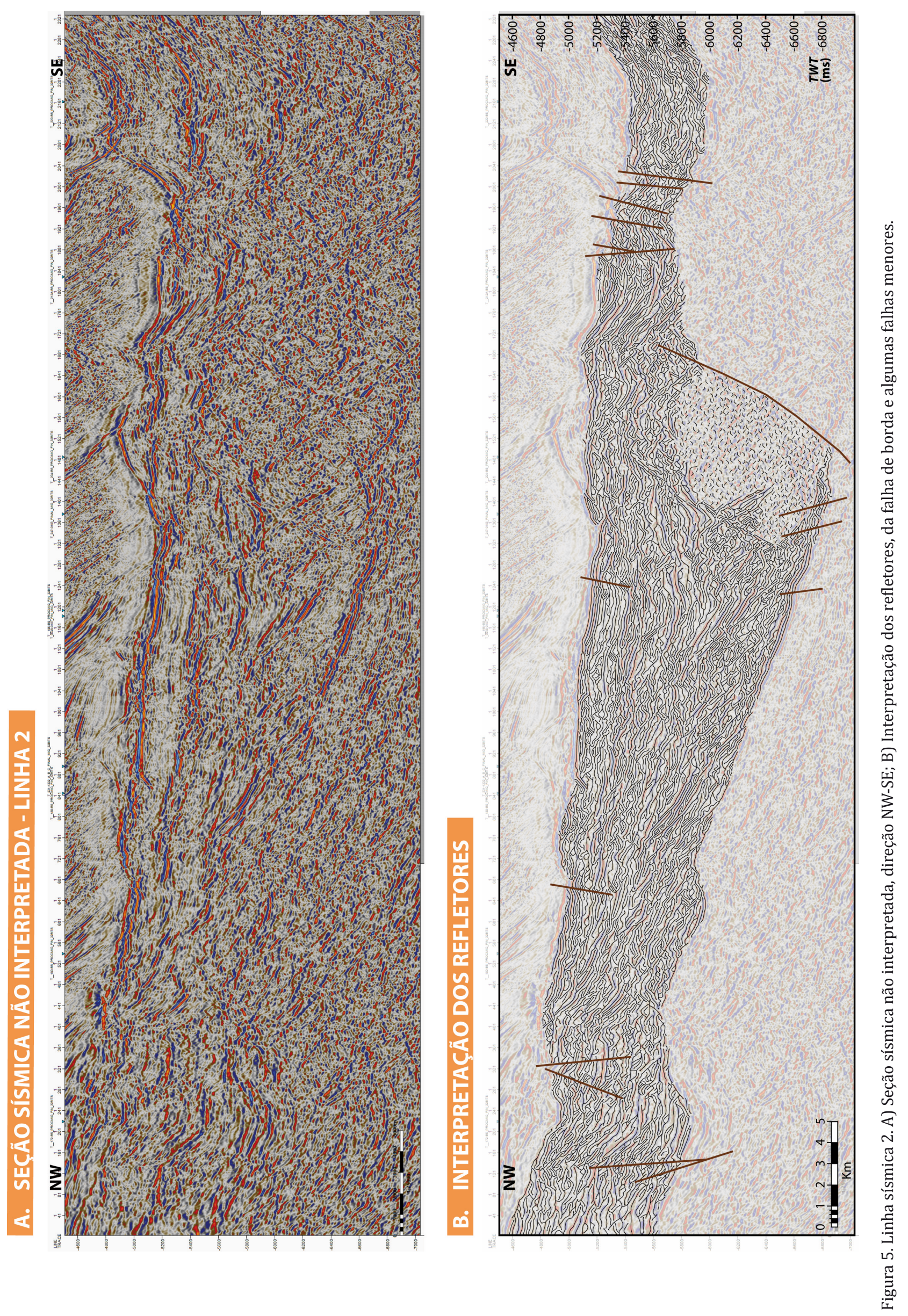

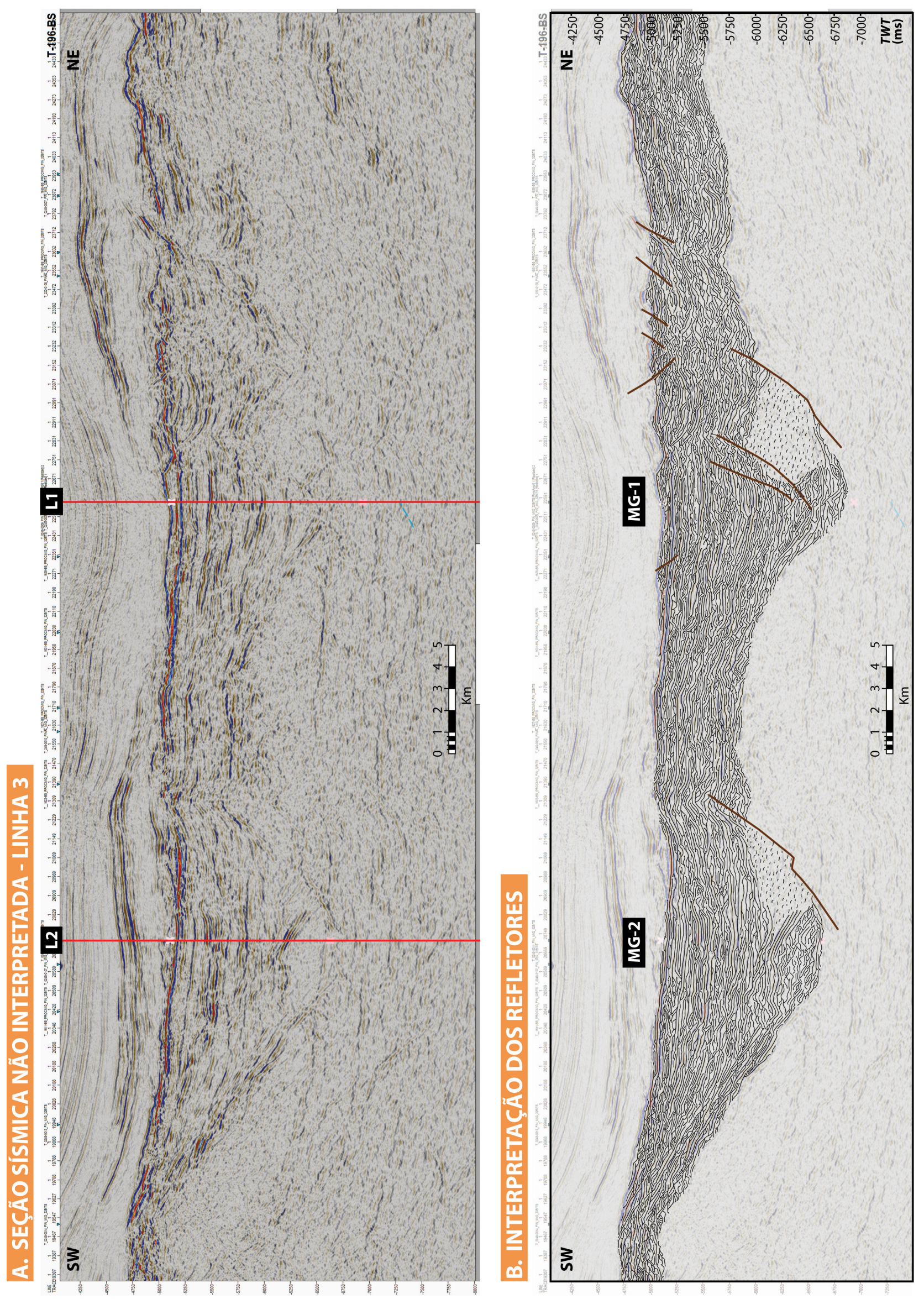

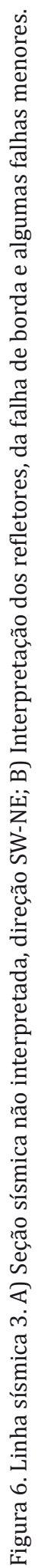


US 10 (onde essa sismofácies tem o maior desenvolvimento), e termina na US 11 (Fig. 8A). Na Linha 3, a SF-A está localizada na zona leste, associada com a falha de borda 1. Esta sismofácies inicia seu desenvolvimento na US 7 e termina na US 10, e a SF-A localizada na zona oeste, associada com a falha de borda 2, só foi reconhecida na US 7 (Fig. 9A). Este tipo de padrão foi interpretado como o reflexo sísmico de sedimentos grossos gerados pela movimentação das falhas de borda.

Na sismofácies B (SF-B) os refletores têm uma configuração de baixa a média amplitude, porém é possível identificar alguns deles com amplitude maior, e tem uma continuidade média, conforme observado na Linha 1 (Fig. 7A). Na Linha 2, os refletores apresentam baixa amplitude, embora alguns tenham amplitude maior. A continuidade e a frequência são médias (Fig. 8A). Na Linha 3 , os refletores apresentam uma amplitude baixa, continuidade média, e frequência de média a alta em toda a seção (Fig. 9A). A SF-B foi interpretada como depósitos de sedimentos finos, e está distribuída ao longo dos meios grábens.

A sismofácies C (SF-C) é composta por refletores com alta amplitude, alta frequência, maior continuidade e configuração divergente. A SF-C é encontrada em lugares específicos dos meio-grábens interpretados. Por exemplo, na Linha 1 este padrão está concentrado principalmente no centro do meio-gráben (Fig. 7A). No caso da Linha 2, esta sismofácies ocorre em diferentes pontos ao longo do todo o meio-gráben, com refletores de alta amplitude, continuidade e frequência. $\mathrm{Na}$ Linha 3, a SF-C foi reconhecida em maior proporção no meio-gráben oeste, mas está distribuída ao longo deste meio-gráben (Fig. 9A). No meio-gráben oeste, as terminações também são de alta amplitude, continuidade e frequência, com configuração subparalela. A SF-C foi interpretada como rochas carbonáticas, devido à resposta sísmica particular dos refletores com alta amplitude, alta frequência, maior continuidade e por similaridade com interpretações sísmicas de reflexões na Bacia de Campos. Segundo Abrahão \& Warme (1990) e Rangel \& Carminatti (2000), estas rochas representam depósitos carbonáticos denominados de coquinas. Assim, dada a continuidade do sistema de rift valley de Campos em direção à Bacia de Santos, e a grande semelhança das reflexões intensas, contínuas e bem definidas dos carbonatos lacustres da Bacia de Campos (Figs. 10A e B), as reflexões da SF-C foram interpretadas como a expressão sísmica destes corpos carbonáticos.

Por fim, a sismofácies D (SF- D) está limitada pela discordância pós-rifte na base, e pela base do sal no topo da seção rifte. Esta sismofácies é rastreável ao longo das linhas por suas características sísmicas, definidas por refletores com continuidade média a alta, com uma configuração de baixa amplitude, porém com algumas áreas com refletores de alta amplitude. Com relação às terminações dos refletores, a SF-D não apresenta um padrão definido. Esta sismofácies foi interpretada como o sag.

\subsubsection{Carta cronoestratigráfica}

Com a integração da informação das terminações dos refletores (onlaps, downlaps, toplaps e truncamentos erosivos), unidades sismoestratigráficas, e sismofácies, foram construídas as cartas cronoestratigráficas de eventos, conforme determinado inicialmente por Wheeler (1958) e adaptado para o contexto sísmico por Vail et al. (1977).

$\mathrm{Na}$ carta cronoestratigráfica da Linha 1 (Fig. 7B) é possível observar o início de desenvolvimento do meio-gráben 1 na US 6, alcançando sua máxima expansão na US 9. Este intervalo é dominado pela SF-B, interpretada como sedimentos finos. Entretanto, ocorre ainda a presença da SF-C, interpretada como carbonatos, e um primeiro pulso da SF-A, associada aos conglomerados gerados pela falha de borda. A partir da US 10, começa uma redução na área da bacia, culminando com a US 14 sendo fortemente afetada pela erosão que gerou a discordância pós-rifte. Este intervalo também é dominado pela SF-B, com ocorrências da SF-C e um segundo pulso de conglomerados (SF-A). O preenchimento final é representado pelas US 15 e US 16, correspondentes a SF-D, interpretadas como sag pelo fato de os sedimentos terem sido depositados no estágio em que as falhas mestras do rifteamento haviam cessado sua atividade ou sofriam raras reativações, dando início à subsidência térmica da bacia rifte (Moreira et al., 2007).

Na carta cronoestratigráfica da Linha 2, se observa o início do desenvolvimento do meio-gráben 2 , que começa na US 1 como uma bacia isolada, dominada por rochas carbonáticas, alcançando sua máxima extensão na US 3 (Fig. 8B). A partir da US 4, ocorre uma redução da bacia até a US 7. Neste intervalo se dá o primeiro pulso de conglomerados, com um hiato na sedimentação que corresponde as US 8 e US 9. Na US 10, há um segundo pulso de extensão da bacia e aparição dos conglomerados, seguido de nova diminuição na área da bacia até a US 14, afetada pela erosão.

Na Linha 3 (Fig. 9B), a carta cronoestratigráfica ressalta os seguintes aspectos: a) início do desenvolvimento do MG-2 na US $1 ; \mathrm{b}$ ) um primeiro 

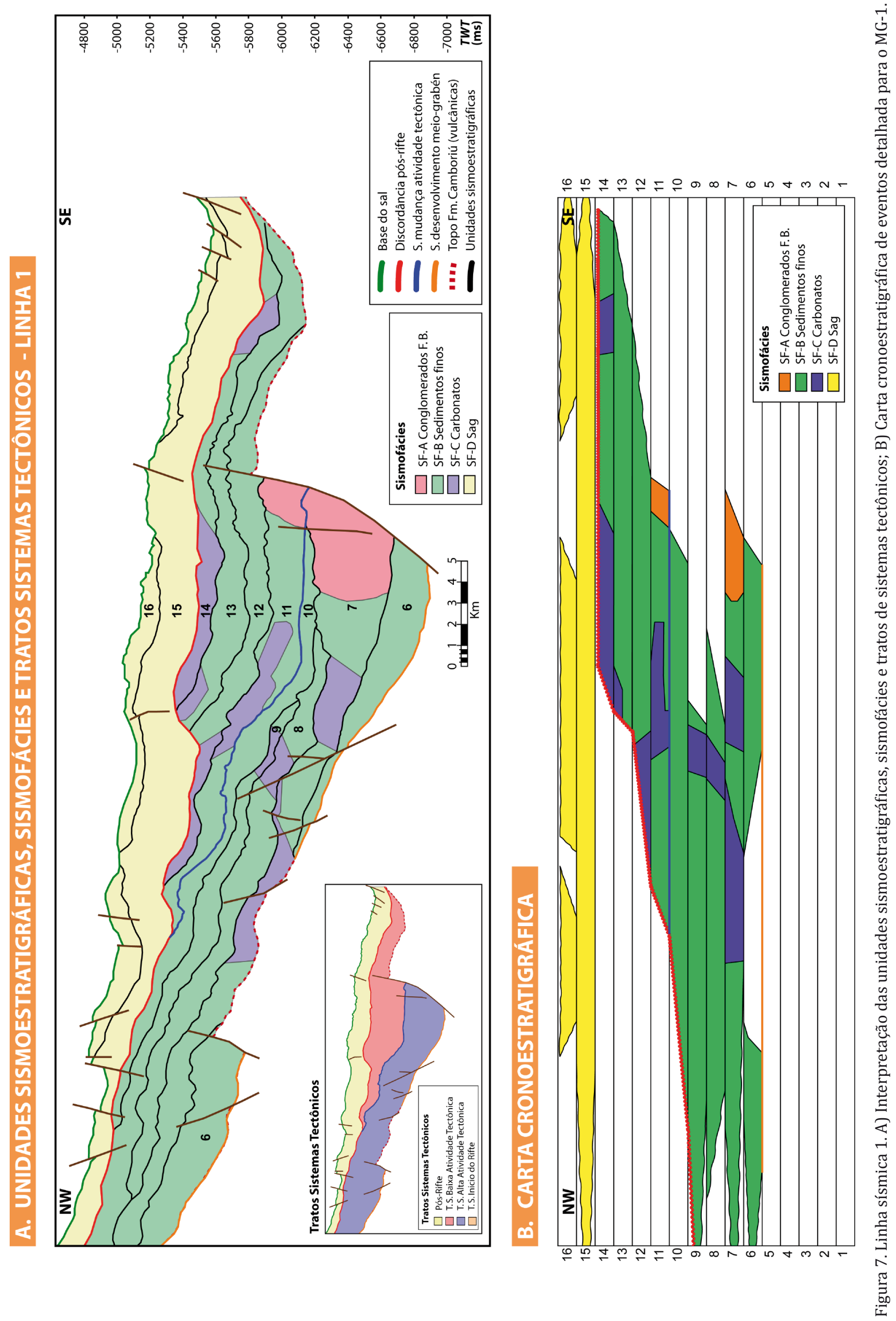


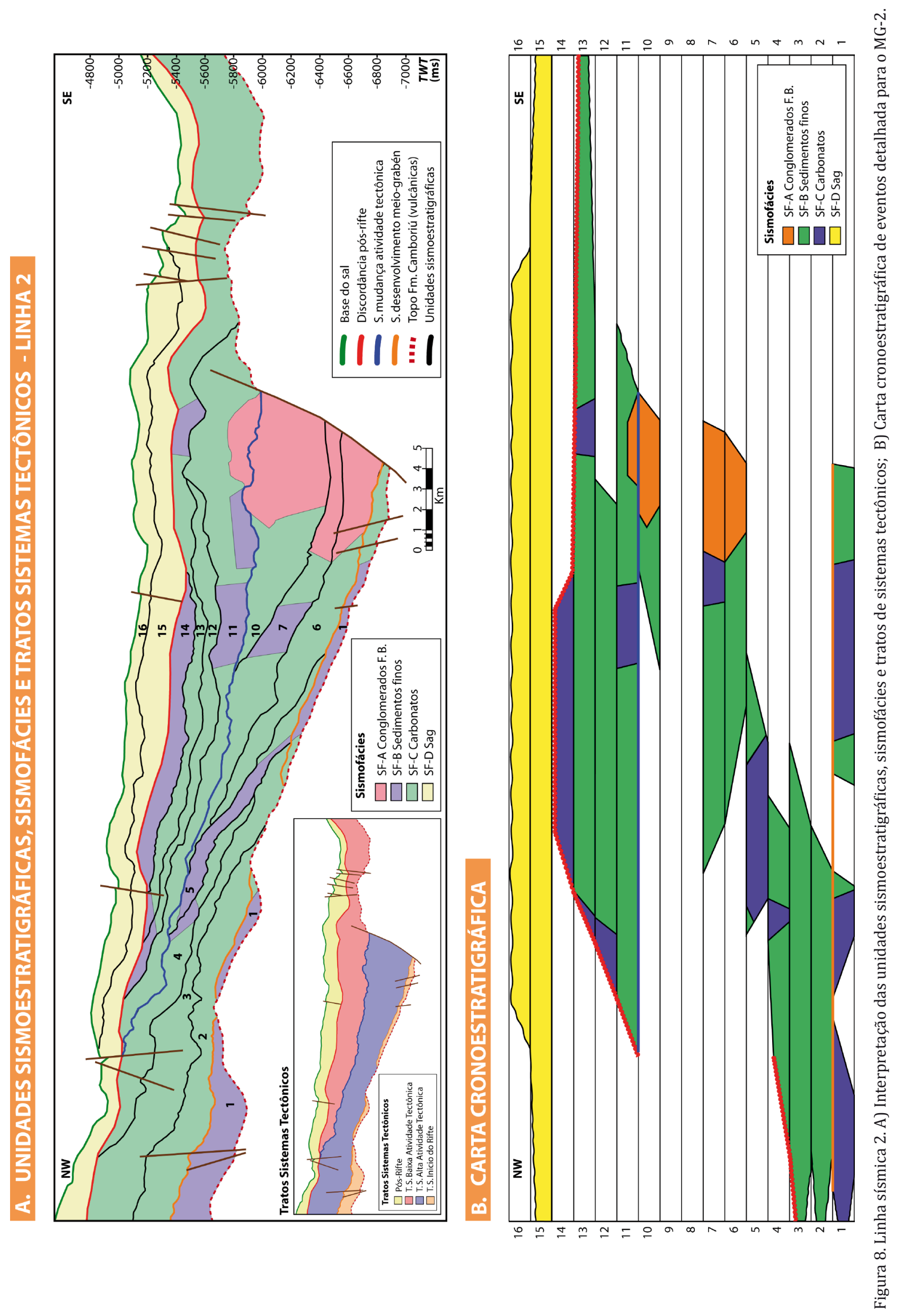



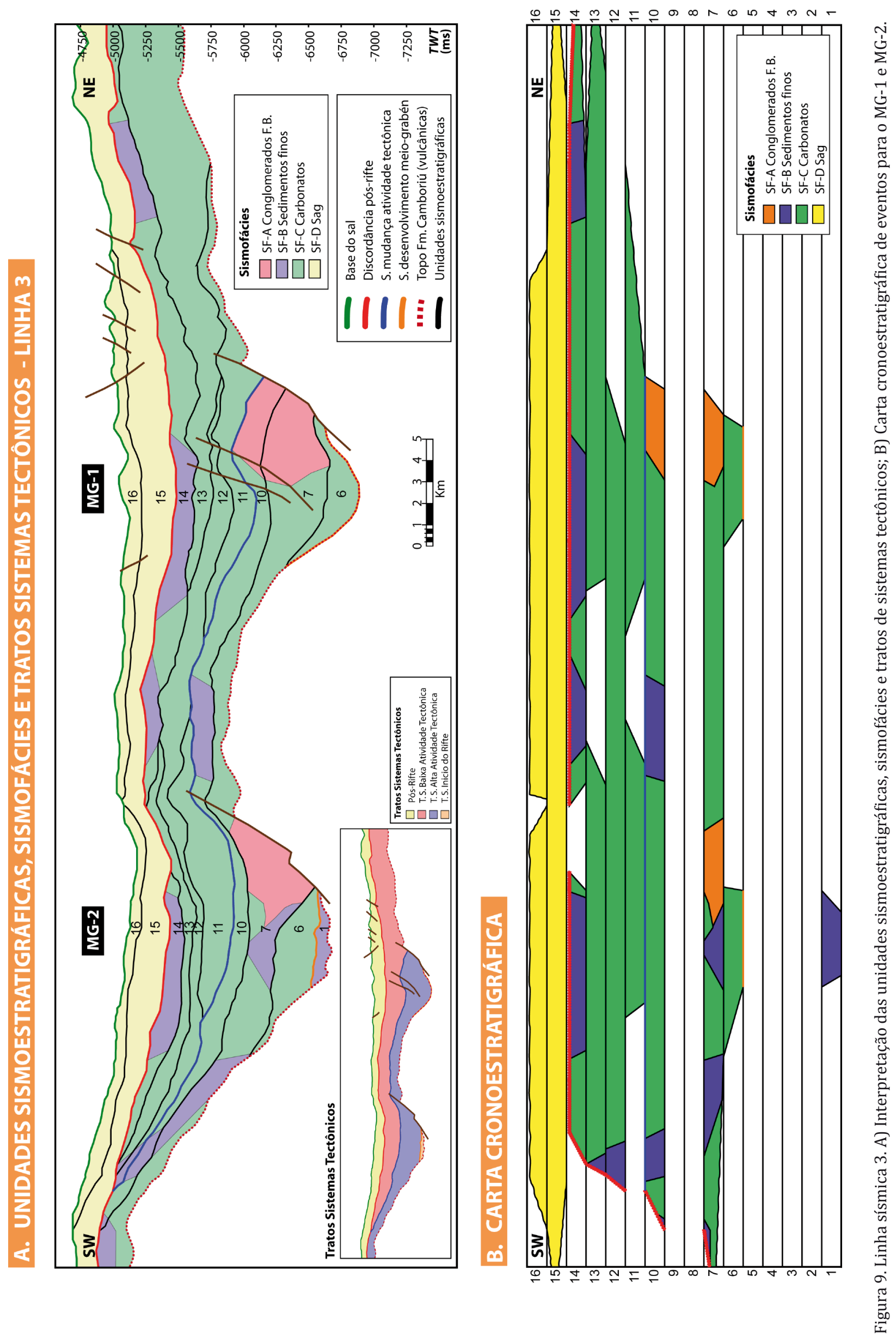

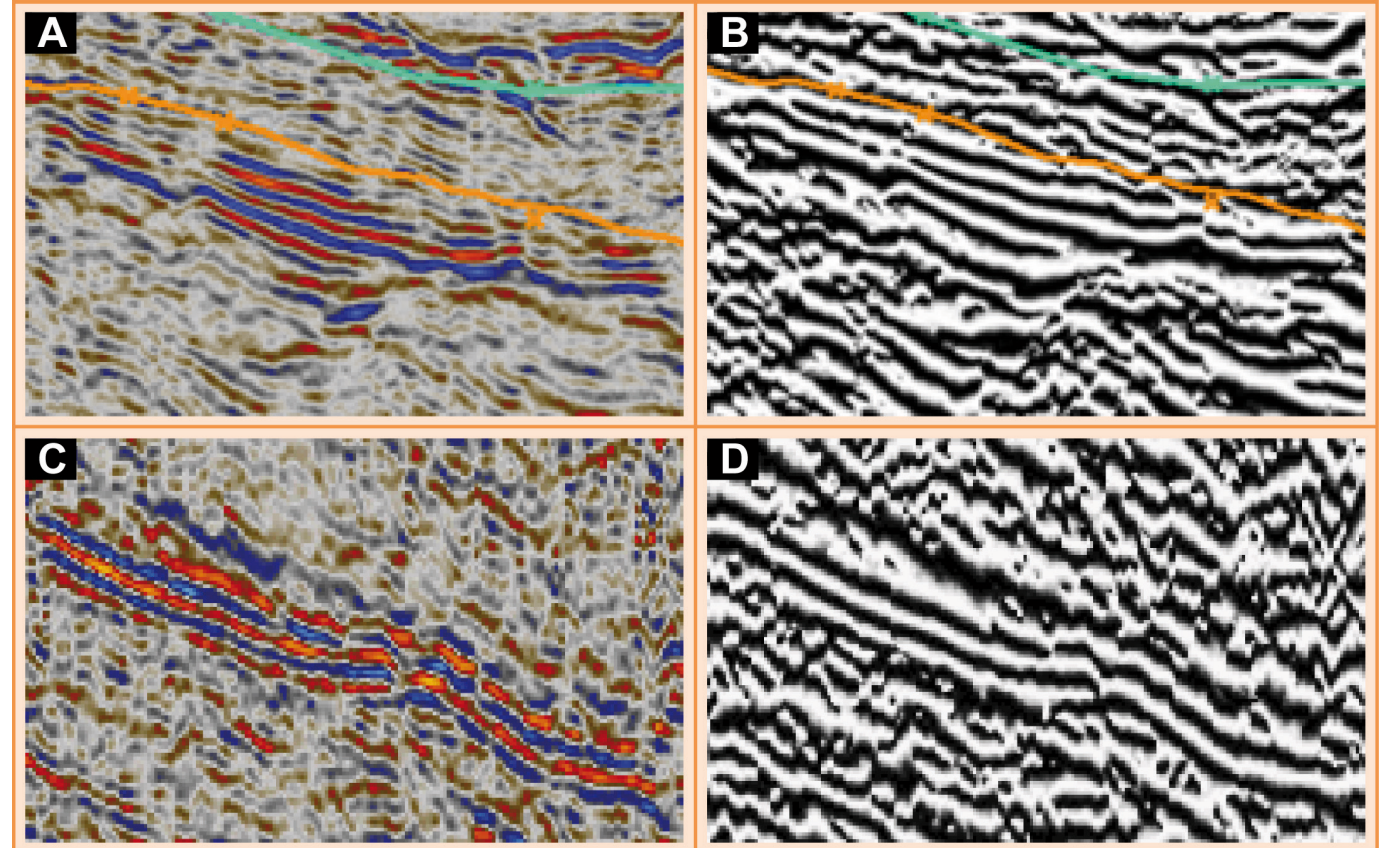

Figura 10. Comparação da SF-C nas bacias de Campos e Santos, usando atributos sísmicos. A) Expressão dos corpos carbonáticos na fase sísmica normal, Bacia de Campos; B) Expressão dos corpos carbonáticos no Cosine phase, Bacia de Campos; C) Expressão dos corpos carbonáticos na fase sísmica normal, Bacia de Santos; D) Expressão dos corpos carbonáticos no Cosine phase, Bacia de Santos.

hiato no qual a US 2 até US 5 não são depositadas; c) início do desenvolvimento do MG-1 na US 6, com máxima extensão do MG-2 até a US 7 e o primeiro pulso de geração de conglomerados associados às falhas de borda; d) um segundo hiato correspondente as US 8 e US 9; e) um segundo pulso de geração de conglomerados associados com a falha de borda 1, aumento na extensão do MG-1 da US 11 até a US 14, e diminuição na bacia do MG-2 da US 10 até a US 14. Nesse intervalo, ocorre a conexão dos dois meio-grábens comportando-se como uma única bacia na US 10 e US 12 .

Por fim, as unidades sismoestratigráficas $15 \mathrm{e}$ 16 , correspondentes à sismofácies D (interpretada como o sag), são marcadas pela erosão na base da US 15 associada com a discordância pós-rifte, e o topo da US 16. Estas unidades são identificadas no topo das três linhas trabalhadas.

\subsubsection{Superfícies estratigráficas e tratos de sistemas tectônicos}

Embora a caracterização das unidades sismoestratigráficas permita a definição dos sucessivos eventos deposicionais que ocorreram nos meio-grábens analisados, o preenchimento destas unidades sismoestratigráficas não apresentou padrão de empilhamento bem definido. 0 padrão de empilhamento progradante, retrogradante ou agradacional, sensu Van Wagoner et al., (1988), é baseado na relação proximal/distal dos sistemas deposicionais, e suas gradações laterais preditas em um sentido dip - paralelo ao eixo deposicional principal. Como a sismofácies SF-A representa depósitos relacionados à falha de borda, o seu avanço ou recuo pode ser relacionado a maiores ou menores descargas de material clástico associado à falha, o que é um reflexo direto do influxo sedimentar + clima e atividade tectônica (Bohacs et al., 2000). Já a relação entre as SF-B e SF-C não apresenta uma relação clara de proximalidade ou distalidade (Figs. 7A, 8A e 9A), o que pode sugerir que os carbonatos caracterizados na SF-C possam ser depósitos ressedimentados na seção mais profunda do lago, enquanto a SF-B pode representar os sedimentos de fundo lacustre (background). Esta hipótese é consistente com a grande quantidade de eventos erosivos observados nas margens flexurais dos meio-grábens analisados.

Sem a definição de padrões de empilhamento na seção estudada, os modelos de Prosser (1993) e Kuchle \& Scherer (2010) não puderam ser usados, o que derivou em uma adaptação dos mesmos, mantendo a denominação de tratos de sistemas tectônicos, mas sem um padrão de empilhamento determinável para cada trato. 0 resultado foi a identificação de um trato de sistemas de início do rifte, um trato de sistemas de alta atividade tectônica, e um trato de sistemas de baixa atividade tectônica.

O Trato de Sistemas de Início de Rifte é limitado na base pela superfície basal do meio-gráben, 
que na Bacia de Santos corresponde ao topo da Formação Camboriú, e no topo pela superfície de desenvolvimento do meio-gráben. Na Linha 2, o trato de sistemas do início de rifte segue a US 1 , e esta unidade apresenta dominantemente a sismofácies SF-C, com algumas pequenas porções de sedimentos finos - SF-B (Fig. 8A). Na Linha 1 não ocorre este trato (Fig. 7A), e neste caso a superfície limite do meio-gráben coincide com sua superfície de desenvolvimento. A Linha 3 tem o registro das duas situações descritas acima: o trato de sistemas de início de rifte na área oeste, composta pela US 1 (dominada pela sismofácies SF-C), enquanto na área leste a superfície do limite do meio-gráben coincide com a superfície de desenvolvimento de meio-gráben (Fig. 9A).

O Trato de Sistemas de Alta Atividade Tectônica é delimitado pela superfície de desenvolvimento de meio-gráben na base, e pela superfície de mudança tectônica no topo. 0 trato é definido por uma alta atividade tectônica, gerando a disposição inclinada das unidades sismoestratigráficas, a erosão de algumas unidades na margem flexural, e a ocorrência dos conglomerados associados com a falha de borda na margem flexural (Figs. 7-9). Na Linha 1, o trato de alta atividade tectônica é composto pelas US 6 , US 7 , US 8 , US 9 , US 10 , onde a sismofácies SF-B predomina; a área central apresenta algumas ocorrências de carbonatos da SF-C e, como consequência da intensa atividade tectônica, são observados os depósitos associados à falha de borda - SF-A (Fig. 7A). No caso da Linha 2 , dentro deste trato se encontram as unidades sismoestratigráficas US 2 até US 7, as US 8 e 9 não são depositadas neste intervalo, e no final do trato é depositada a US 10; a sismofácies que domina é a SF-B, composta por depósitos de sedimentos finos, mas também são encontradas ocorrências isoladas de carbonatos da SF-C, e observados os conglomerados associados à movimentação da falha de borda (SF-A). Estes aparecem na US 6 e alcançam a US 10 (Fig. 8A). Em relação à Linha 3, o trato corresponde às US 6, US 7 e US 10. As US 8 e 9 não foram depositadas. Em geral, os depósitos de sedimentos finos (SF-B) são dominantes, entretanto são encontradas ocorrências de carbonatos da SF-C com maior frequência na zona oeste. Com relação aos conglomerados da falha de borda, o maior desenvolvimento se encontra na área leste, com os depósitos de conglomerados começando na US 7 e indo até US 10; na área oeste os depósitos de conglomerado terminam na US 10 (Fig. 9A).

0 Trato de Sistemas de Baixa Atividade Tectônica é delimitado na base pela superfície de mudança de atividade tectônica, e no topo pela dis- cordância pós-rifte. Este trato é marcado por uma diminuição na atividade tectônica, com desaparecimento dos conglomerados gerados pela falha de borda (SF-A) e unidades sismoestratigráficas mais contínuas ao longo do meio-gráben. Na Linha 1, o trato corresponde às US 11, 12, 13 e 14; os depósitos dominantes são sedimentos finos (SF-B), mas também se encontram faixas mais contínuas de carbonatos (SF-C). Os conglomerados (SF-A), associado à falha de borda, só são observados na US 11 (Fig. 7A). No caso da Linha 2, o trato contém as US $11,12,13$ e 14 . Este trato é dominado pelos sedimentos finos (SF-B), apesar de serem encontrados carbonatos (SF-C) isolados em toda a US 14 e pequenas acumulações dos conglomerados de falha de borda (Fig. 8A). A Linha 3 apresenta a mesma situação das outras duas: 0 trato está representado pelas US 11,12, 13 e 14, onde dominam os depósitos de sedimentos finos. Neste caso os carbonatos estão restritos a faixas dentro da US 14 ao longo da estrutura, e o conglomerado é observado numa pequena zona na área leste (Fig. 9A).

Por fim, o pós-rifte, na análise realizada, é representado pela sismofácies D. Este está delimitado na base pela discordância pós-rifte, e no topo pela base do sal. No estágio pós-rifte se observa continuidade ao longo dos meio-grábens estudados. Na Linha 1 , o pós-rifte corresponde às unidades sismoestratigráficas 15 e 16, situação similar nas linhas 2 e 3 (Figs. 7, 8 e 9).

\subsection{Modelo evolutivo do rifteamento}

A análise dos tratos de sistemas tectônicos levou em conta a relação de dois fatores controladores das bacias lacustres: a atividade tectônica (responsável pela criação do espaço da acomodação), e o aporte sedimentar + água (função da umidade climática), segundo as premissas de Bohacs et al. (2000). Como consequência, os lagos contêm volumes menores de sedimento e água, comparado com um sistema de deposição marinha; por isso, o sistema lacustre é mais sensível a mudanças no espaço de acomodação e no clima. 0 nível do lago e o aporte sedimentar estão diretamente ligados ao sistema do lago (variações na descarga fluvial). A influência do clima nas variações do nível de base é mais pronunciada em bacias lacustres equilibradas e fechadas, onde o suprimento de água é periodicamente negativo (Keighley et al., 2003). Finalmente, a natureza e existência do lago são fundamentalmente controladas pela taxa relativa entre potencial de acomodação e aporte sedimentar; clima e tectônica, que exercem controles equivalentes sobre a natureza e distribuição dos tratos 
de sistemas tectônicos.

A figura 11 apresenta a interpretação dos tratos de sistemas tectônicos definidos neste trabalho para a Bacia de Santos em relação aos modelos de bacias lacustres definidos por Bohacs et al., (2000).

No trato de sistemas de início do meio-gráben, que corresponde à US 1 , a taxa do aporte sedimentar e o espaço de acomodação estão balanceados (Balanced-fill). Este estágio apresenta uma tectônica incipiente associada ao estiramento crustal da fase rifte, gerando pequenas bacias isoladas que são preenchidas pelo aporte de sedimento ligado ao nível do lago, e ao aporte fluvial variável em um sistema hidrológico intermitentemente aberto, próprio de cada lago. 0 influxo de água é suficiente para encher periodicamente o espaço disponível, acompanhando as flutuações do nível do lago devido ao clima. Nestas fases iniciais, o baixo aporte sedimentar decorre também de áreas de drenagem pequenas e fragmentadas, e o fornecimento de sedimentos axiais é limitado (Keighley et al., 2003).

No trato de sistemas de alta atividade tectônica, correspondente a US 2 até a US 10, o espaço de acomodação gerado pela intensa atividade tectônica da bacia, associada ao desenvolvimento da falha de borda, é muito maior que o aporte sedimentar. Ou seja, não há quantidade de sedimentos suficiente para preencher o espaço gerado (Underfilled). Esta fase apresenta mínimo aporte sedimentar fluvial e ciclos de alta frequência úmido - seco.

\begin{tabular}{|r|c|c|c|}
\hline US & $\begin{array}{c}\text { Trato Sistema } \\
\text { Tectônico } \\
16\end{array}$ & Sag & \multicolumn{2}{|c|}{ Não Analisado } \\
(Bohacs et al., 2000)
\end{tabular}

Figura 11. Análise dos tratos de sistema tectônicos definidos para a Bacia de Santos em relação aos fatores controladores numa bacia lacustre: atividade tectônica, aporte sedimentar e clima (segundo Bohacs et al., 2000).

Por isso é comum se observar a disposição inclinada das unidades sismoestratigráficas, erosão e não deposição de algumas unidades neste trato.

No trato de sistemas de baixa atividade tectônica, compreendendo às US 11 até 14 , a bacia se encontra sobrecarregada (Overfilled). Neste caso, a taxa de aporte sedimentar consistentemente excede o potencial de acomodação em função da diminuição da subsidência. A geometria deposicional neste estágio reflete as mudanças do fluxo dos sedimentos, onde apresenta um maior aporte fluvial e flutuações no nível da bacia impulsionado pelo clima. Na interpretação das linhas sísmicas é possível observar algumas unidades sismoestratigráficas que se estendem ao longo dos dois meio-grábens, como no caso da Linha 3, que durante determinado intervalo se comportou como uma única bacia ou lago.

\section{Conclusões}

O presente trabalho, desenvolvido na seção rifte da Bacia de Santos, teve por objetivo unir a assinatura sismoestratigráfica com modelos que tem ênfase na evolução tectono-estratigráfica de bacias rifte, e chamar a atenção para a seção rifte como uma nova fronteira exploratória.

A interpretação sismoestratigráfica de três linhas sísmicas de boa qualidade, onde foram definidos refletores sísmicos, terminações dos refletores e sismofácies, permitiu a definição de 16 unidades sismoestratigráficas, as quais possuem um significado temporal e proporcionam a compreensão do desenvolvimento e evolução dos meio-grábens caracterizados. A utilização dos atributos sísmicos Cosine Phase, Sweetness, Relative Acoustic Impedance (RAI), RMS Amplitude, a partir da sísmica em 
normal phase, apresentou bons resultados para a interpretação sismoestratigráfica.

Baseado nos parâmetros sísmicos, geometria da reflexão, continuidade, amplitude, frequência, e intervalo de velocidade, foram caracterizadas quatro sismofácies: a) SF-A, depósitos associados à falha de borda; b) SF-B, depósitos de sedimentos finos; c) SF-C, depósitos carbonáticos e d) SFD, depósitos do sag (fora do intervalo de estudo). Pela similaridade com interpretações sísmicas de seções na Bacia de Campos, e devido à resposta sísmica particular dos refletores com alta amplitude, alta frequência, maior continuidade, a SF-C foi interpretada como compreendendo carbonatos lacustres.

Com a integração da informação de terminações dos refletores, unidades sismoestratigráficas, e sismofácies, foram construídas cartas cronoestratigráficas de eventos para cada um dos meio-grábens interpretados. 0 modelo de Prosser (1993) e Kuchle \& Scherer (2010) foi adaptado na proposição de um modelo de evolução da seção rifte da Bacia dos Santos, que inclui três tratos de sistemas tectônicos na seção rifte. 0 Trato de Sistemas de Início de Rifte é limitado na base pela superfície basal do meio gráben e no topo pela superfície de desenvolvimento do meio-gráben, e representa depósitos clásticos relacionados à fase inicial do rifteamento, onde a bacia não apresenta uma falha de borda bem definida e sua geometria é sinformal. 0 Trato de Sistemas de Alta Atividade Tectônica é delimitado pela superfície de desenvolvimento de meio-gráben na base e pela superfície de mudança tectônica no topo, e representa depósitos relacionados à fase de intensa atividade tectônica, caracterizada por uma geometria de meio-gráben bem definida, com depósitos de falha de borda e refletores divergentes, resultado de atividade tectônica sindeposicional. 0 Trato de Sistemas de Baixa Atividade Tectônica é delimitado na base pela superfície de mudança de atividade tectônica e no topo pela discordância pós-rifte. Este último representa depósitos relacionados a uma fase de diminuição da atividade tectônica, onde o meio-gráben é extravasado e os refletores apresentam suaves divergências e dominante paralelismo, o que indica uma baixa atividade tectônica relativa.

A análise dos tratos tectônicos definidos neste trabalho, com relação aos fatores controladores das bacias lacustres (Bohacs et al., 2000), sugere que o trato de sistemas de início de rifte se desenvolveu em uma bacia onde a atividade tectônica e o aporte sedimentar eram balanceados. No trato de sistemas de alta atividade tectônica ocorreu a geração de uma grande quantidade de espaço que não é preenchido, e por fim, no trato de sistemas de baixa atividade tectônica, a taxa de aporte sedimentar era muito maior que o espaço de acomodação devido à diminuição da subsidência tectônica.

Agradecimentos Este estudo constitui parte da dissertação de mestrado da primeira autora (AAR) junto ao Programa de Pós-graduação em Geociências da UFRGS, integrada ao Projeto Deep Rift, desenvolvido em parceria entre a Universidade Federal do Rio Grande do Sul e a BG Brasil, amparado pela Lei do Petróleo. Agradecemos especialmente ao Global Technology Centre da BG Brasil pelo apoio financeiro e contribuições técnicas ao projeto. Adicionalmente, agradecemos à ANP pelo compromisso com investimentos em pesquisa e desenvolvimento.

\section{Referências}

Abrahão, D. \& Warme, J.E. 1990. Lacustrine and associated deposits in a rifted continental basin - Lower Cretaceous Lagoa Feia Formation, Campos basin, Offshore Brazil. In: Katz, B.J. (Ed.). AAPG Memoir 50 - Lacustrine Basin Exploration - Case Studies and Modern Analogs. Tulsa, American Association of Petroleum Geologists, p. 287-305.

Bosence, D.W.J. 1998. Stratigraphic and sedimentological models of rift basins. In: Purse, B.H. \& Bosence, D.W.J., (Eds.). Sedimentation and Tectonic of Rift Basins: Red Sea - Gulf of Aden. Londres, Chapman \& Hall, p. 9-25.

Bohacs, K.M., Carroll, A.R., Neal, J.E. \& Mankiewicz, P.J. 2000. Lake-basin type, source potential, and hydrocarbon character: an integrated-sequence-stratigraphic-geochemical framework. In: Gierlowski-Kordesch, E.H \& Kelts, K.R. (Eds.). Lake basins through space and time. AAPG Studies in Geology, 46: 3-34.

Brown Jr., L.F. \& Fisher, W.L. 1977. Seismic-Stratigraphic Interpretation of Depositional Systems: Examples from Brazilian Rift and Pull-Apart Basins: Section 2. Application of Seismic Reflection Configuration to Stratigraphic Interpretation. Seismic stratigraphy Applications to hydrocarbon exploration. American Association of Petroleum Geologists, 26: 213-248

Catuneanu, 0. 2006. Principles of Sequence Stratigraphy. Amsterdam, Elsevier, 375 p.

Catuneanu, O., Galloway, W.E., Kendall, C.G.St.C., Miall, A.D., Posamentier, H.W., Strasser, A. \& Tucker, M.E. 2011. Newsletters on Stratigraphy, 44(3):173-245.

Chang, H.K., Assine, M.L., Corrêa F.S., Tinen J.S., Vidal, A.C. \& Koike, L. 2008. Sistemas petrolíferos e modelos de acumulação de hidrocarbonetos na Bacia de Santos. Revista Brasileira de Geociências, 38(2): 2946.

Contreras, J., Zühlke, R., Bowman, S. \& Bechstädt, T. 2010. Seismic stratigraphy and subsidence analysus of the southern Brazilian margin (Campos, Santos and Pelotas basins). Marine and Petroleum Geology, 
27: 1952-1980.

Gawthorpe, R.L., \& Leeder, M.R., 2000, Tectono-sedimentary evolution of active extensional basins. $\mathrm{Ba}$ sin Research, 12:195-218.

Haq, B.U., Hardenbol, J. \& Vail, P.R. 1987. Chronology of fluctuating sea levels since the Triassic (250 million years ago to present). Science, 235: 1156-1166.

Keighley, D., Flint, S., Howell, J. \& Moscariello, A. 2003. Sequence stratigraphy in lacustrine basins: a model for part of the Green River Formation (Eocene), southwest Uinta Basin, Utah, USA. Journal of Sedimentary Research, 73(6): 987-1006.

Kuchle, J. \& Scherer, C.M.S. 2010. Sismoestratigrafía de bacias rifte: técnicas, métodos e sua aplicação na Bacia de Recôncavo. Boletim de Geociências da Petrobras, 18(2): 33-60.

Macedo, J.M. 1990. Evolução tectônica da Bacia de Santos e áreas continentais adjancentes. In: Raja Gabaglia G.P. \& Milani, E.J. (Eds.), Origem e Evolução de Bacias Sedimentares. Rio de Janeiro, Petrobrás, p. 361-376.

Milani, E.J., Brandão, J.A.S.L., Zalán, P.V. \& Gamboa, L.A.P. 2000. Petróleo na margem continental brasileira: Geologia, exploração, resultados e perspectivas. Revista Brasileira de Geofísica, 18(3): 351-396.

Milani, E.J. \& Thomaz Filho, A. 2000. Sedimentary basins of South America. In: Cordani U.G., Milani, E.J., Thomaz Filho, A. \& Campos, D.A. (Eds.), Tectonic evolution of South America. Rio de Janeiro, p. 389-449.

Mitchum Jr., R.M., Vail, P.R. \& Sangree, J.B. 1977. Seismic stratigraphy and global changes of sea level, part 6: Interpretation of seismic reflection patterns in depositional sequences. In: Payton C.E. (Ed). AAPG Memoir 26 - Seismic stratigraphy - Applications to hydrocarbon exploration. Tulsa, American Association of Petroleum Geologists, p. 117-133.

Morley, C.K. 2002. Evolution of large normal faults: Evidence from seismic reflection data. American Association of Petroleum Geologists Bulletim, 86(6): 961-
978.

Moreira, J.L.P., Madeira, C.V., Gil, J.A. \& Machado, M.A.P. 2007. Bacia de Santos. Boletim de Geociências da Petrobras, 15(2): 531-549.

Prosser, S. 1993. Rift-related linked depositional systems and their seismic expression. In: Williams, G.F. \& Dobb, A. (Eds.). Geological Society Special Publication, 71 - Tectonics and Seismic Sequence Stratigraphy. Londres, Geological Society of London, p. 35-66.

Rangel, H.D. \& Carminatti, M. 2000. Rift lake stratigraphy of the Lagoa Feia Formation, Campos Basin, Brazil. In: Gierlowski - Kordesch, E.H. \& Kelts, K.R., (Eds.). AAPG Studies in Geology 46 - Lake basins through space and time. Tulsa, American Association of Petroleum Geologists, p. 225-244.

Schroeder, W.F. 2011. An Introduction to the Hunt For Oil for Geoscientists not within Industry. Unit 13: Seismic Attributes. American Association of Petroleum Geologists, Slide Resources. Disponível em: <http://archives.aapg.org/slide_resources/schroeder/13/index.cfm>

Vail, P.R., Mitchum Jr., R.M., Todd, R.G., Widmier, J.M., Thompson III, S., Sangree, J.B., Bubb, J.N. \& Hatlelid, W.G. 1977. Seismic stratigraphy and global changes of sea level, part 3: Relative changes of sea level from coastal onlap. In: Payton C.W., (Ed.). AAPG Memoir 26 - Seismic stratigraphy - applications to hydrocarbon exploration. Tulsa, American Association of Petroleum Geologists, p. 63-97.

Van Wagoner, J.C., Posamentier, H.W., Mitchum, R.M., Vail, P.R., Sarg, J.F., Loutit, T.S., Hardenbol, J. 1988. An overview of sequence stratigraphy and key definitions. In: Wilgus, C.K., Hastings, B.S., Kendall, C.G.St.C., Posamentier, H.W., Ross, C.A., Van Wagoner, J.C. (Eds.). SEPM Special Publication 42 - Sea Level Changes - An Integrated Approach, p. 39-45.

Wheeler, H.E. 1958. Time-stratigraphy. American Association of Petroleum Geologists Bulletin, 42: $1047-$ 1063.

Man 540

Editores: Iran S. Correa \& Paulo A. Souza. 